\title{
Development of an algorithm for investigation of technical state of wagons' running gears during their derailment
}

\author{
Andriy Batig ${ }^{1 *}$, Petro Hrytsyshyn ${ }^{1,2,3}$, Andriy Kuzyshyn ${ }^{1,3,4}$, Andriy Milyanych ${ }^{3}$, Oleh Voznyak $^{1,3}$, and Yuriy Tereshchak ${ }^{3}$ \\ ${ }^{1}$ Lviv Research Institute of Forensic Science, 79000 Lviv, Ukraine \\ ${ }^{2}$ Western center of the Ukrainian branch of the World laboratory, 79021 Lviv, Ukraine \\ ${ }^{3}$ Lviv branch of Dnipro National University of Railway Transport named after Academician V. Lazaryan, 79052 Lviv, Ukraine \\ ${ }^{4}$ Dnipro National University of Railway Transport named after Academician V. Lazaryan, 49000 Dnieper, Ukraine
}

\begin{abstract}
A freight wagon is a collection of a large number of parts and assemblies that form a single structure. During wagon operation, there are gradual changes in the characteristics and parameters of its structural elements. That is, the parameters of its constituent elements change - their numerical values increase or decrease that result in a change of the unit's technical state, and, in turn, affects the totality of its performance. Gradually accumulating, the changes in the parameters of the structural elements of a wagon reach such a level that radical, sometimes abrupt qualitative change occurs. A malfunction that has not been repaired timely may lead to a failure of a wagon structural element, which, in turn, may result in rolling stock derailment. It has been established that the loss of stability of freight wagons during their movement is most often due to their unsatisfactory dynamic properties, which can be explained by design features and technical state of running gears. In this regard, the authors of the article have developed an algorithm for investigation technical state of running gears of freight wagons and determined the effect of their parameters' deviation on rolling stock operation with possible further derailment.
\end{abstract}

\section{Introduction}

The ability of the railway transport to meet the needs for passengers and cargo transportation with unconditional security of traffic determines the development and achievement of its leading position in the transportation market. One of the most important problems on railway transport is the safety of trains traffic both at design stage and in the process of transport operation. At the same time prevention of transport incidents on railways is of primary importance [1].

Of the total number of transport incidents on the Ukrainian railways, a significant part of the cases is rolling stock derailment, and the task is a cause-andeffect analysis of factors that contribute to their development.

Such factors may be the characteristics and parameters of the technical state of the running gears of wagons that have derailed, the state of the railway track at the section of derailment, the formation scheme and mode of train operation, etc.

The investigation of cases of railway traffic accidents has shown for the recent years that there is an increasing number of cases of empty freight wagons derailment in trains. Such cases were most often provoked by unsatisfactory dynamic properties of wagons, which are primarily determined by the design features and technical state of their running gears and the condition of the railway track [2].
Therefore, the development and improvement of methods for assessing the impact of the rolling stock technical sate on its dynamic behavior is an important part in traffic accidents prevention on railways.

\section{Analysis of literary data and problem statement}

A considerable amount of scientific work is devoted to investigation of trains stability and effect their running gears technical state on traffic safety.

Among them, it is necessary to highlight the work [3], which outlines the main types of rolling stock derailment; their main causes have been considered and recommendations as for the maintenance of rolling stock and railway track technical state have been given to prevent railway traffic accidents.

The problem of derailment of empty wagons was investigated in [4]. The authors of this work propose a new scheme of a spring set of a freight bogie 18-100, which includes three-component wedges and springloaded sliders.

The calculations and tests on the use of such elements have shown the improvement of dynamic parameters of empty wagon movement and the reduction stress of side frames of bogies.

In the work [5] the main attention is paid to the investigation of the impact of various factors of the technical state of freight wagons running parts

Correspond ing author: batigasha1992@gmail.com 
(deviations in size both in sliders and in the wedge system) on their main dynamic indicators. This made it possible to assess objectively the impact of the technical state of bogie sliders on traffic safety indicators.

The authors of the paper [6] have considered the issues of stability against wheel flange of a freight wagon rollover on the head of the rail for different models of empty four-wheeled freight wagons with bogie models 18-100 (TSNII-H3). In this paper, the authors investigated the influence of technical characteristics of a wagon for the period of time during which a wheel flange rolling onto rails occurs in the process of wagon movement in curved sections of the track.

In the paper [7], the authors carried out a thorough investigation of train movement stability and the mechanism of its derailment; the impact of defects in the running parts of rolling stock and rail track on the occurrence of railway traffic accidents was established.

In the paper [8], the authors performed the statistical analysis of causes of the railway traffic accidents that occurred on the US railways between 2001 and 2010. It showed that the main causes of accidents and disasters on the US railways were rails breakage due to improper braking at speeds up to $10 \mathrm{mph}$. In turn, bearings malfunction, wheels breakage, defects of axes and necks were the main causes of railway traffic accidents during trains running at speeds greater than $25 \mathrm{mph}$.

In the paper [9], the author notes that one of the important tasks concerning rolling stock maintenance in operating condition is the diagnosis of axle-box unit of the running gear, which allows timely detect malfunctions of their elements and thus avoid the occurrence of railway traffic accidents. On the basis of this, the author of this work carried out theoretical and experimental researches of axle-box bearings by diagnosing their parameters and it was established that the rate of various types of defects development in the elements of their structure is not the same.

The methodical manual that describes many obvious and hidden causes of rolling stock derailment on Russian railways is the work [10]. It contains methods and technics of conducting official investigation of accidents with trains caused by the force influence of rolling stock units on the elements of the upper structure of the track. Along with the statement of recommendations on determining the causes of rolling stock derailment, some proven in practice recommendations in the field of maintenance of the technical state of rolling stock and rail track during operation are provided.

In the railway-transport expertise, approaches as for establishing the technical state of rolling stock were developed by Sokol E.M. In his monograph [11], the main attention was paid to the development of the theory of rolling stock derailment in the case of wheel rolling onto the head of the rail, in the event of a rail track breaking, as well as in the case of vehicles collision. The author of this work noted that in order to establish the causes of rolling stock derailment and the mechanism of a railway accident occurrence, the grounded research should be conducted concerning rolling stock technical state, the railway track, the devices of signaling, centralization and interlocking as well as communication, and actions of persons who are responsible for their maintenance.

In the work [12] the authors specified the objects of railway transport expertise and, based on the description of railway accident circumstances, the recommendations were given as for establishing technical state of elements of the rolling stock structure in accordance with DSTU 2860-94.

As can be seen from the analysis of the abovementioned literary sources, the problems of ensuring stability of rolling stock movement, determining the causes and conditions of its derailment remain urgent at present. Identification of such causes is a rather difficult task with respect to a large number of factors contributing rolling stock derailment and uncomplete information as for various causes or their coincidence in a specific rail accident. In turn, the availability of an algorithm for investigating the impact of the technical state of wagons' running gears on the probability of their derailment would greatly simplify and deepen the detection of causes of railway traffic accidents.

\section{Purpose and objectives of the research}

The aim of the work is to investigate the influence of the technical state of wagons' running gears on the cases of their derailment.

Objectives of the investigation:

- to analyze the causes of the rolling stock derailment on the railways of Ukraine for the last five years;

- to investigate the influence of design features and technical state of wagon's running gears on railway traffic incidents;

- to develop an algorithm for assessing the impact of the technical state of running gears of freight wagons on their derailment.

\section{Investigation of causes of freight wagons derailment on the railways of Ukraine for the past five years}

There have been 2746 railway and transport incidents on Ukrainian railways for the last five years, where 639 cases are conditioned by the malfunctions in the construction of freight wagons [13].

All malfunctions of wagons that resulted in railway transport incidents can be distributed as follows: shocktraction equipment malfunctions - 8.29\%, brake equipment malfunctions - 38.81\%, malfunctions of bodies and frames $-6.1 \%$, malfunctions of running gear $-43,97 \%$, others $-2,82 \%$ (Fig. 1 ).

As can be seen from (Fig. 1), the greatest percentage of malfunctions of wagons falls on their running gear.

The malfunctions of rolling stock running gears that were the causes of railway transport incidents include: - excessive wear of the supporting surfaces of axlebox slots of the lateral frames, sloping surfaces of oversprung beams, thrust-bearings, friction wedges and slats; 
- over standard gaps between the guiding rails of the axlebox bodies and side frames, the bogie sliders and wagon frames;

- weakening and breakage of the end mounting of axlebox, bearings;

- spalling, sliders, buildups on the rolling rail surface, fine-dimensional flanges of wheel-pairs, their vertical cutting and sharp-end rollover.

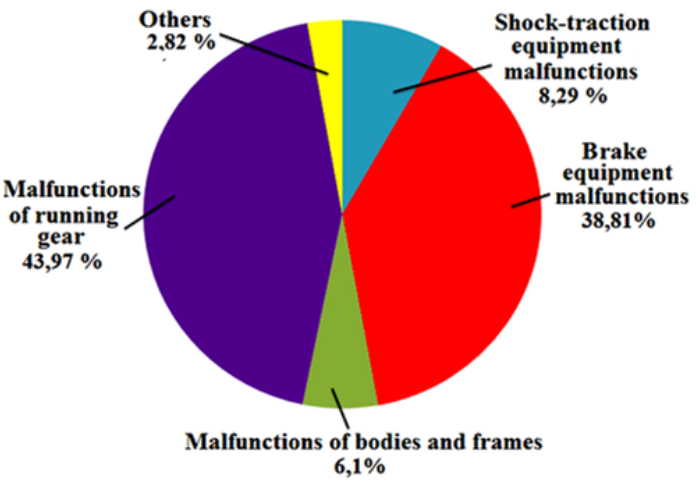

Fig. 1. Diagram of malfunctions of freight wagon distribution, which were the causes of railway traffic accidents for the last 5 years

The appearance of above-mentioned malfunctions of the running gears is due to the fact that they are one of the most important elements of the wagon structure, through which the transfer of all loads from the body to the track, as well as the adoption of a significant part of traction and braking effort takes place.

Therefore, the presence of wear, defects of design and operational nature in the elements of the running gear structure directly affects the operational reliability of freight wagons and it is one of the main reasons for stability loss during their movement and, consequently, derailment.

There have been about 176 derailments of freight wagons in trains on the railways of Ukraine for the last 5 years [13].

Depending on the reasons and in accordance with the existing classification, the reasons for rolling stock derailment were as follows: due to discontinuity of the track $-30.14 \%$, train displacement $-3.98 \%$, rail track shift $-1.13 \%$, rollover of the cut wheel flange at the turnover $-2,27 \%$, arrow cut $-11,36 \%$, collision of rolling stock $-18,18 \%$, rail breakage $-0,57 \%$, others $32,3 \%$ (Fig. 2).

Under other causes of rolling stock derailment, according to the authors of this work, which should be included in the general list, there are cases of rolling stock derailment due to its unsatisfactory interaction with the rail track, damage of rolling stock structure components, rolling stock rollover on outside objects.

Accidents of rolling stock derailment due to the damage of rolling stock structure components, rolling stock rollover on outside objects amounted to $5 \%$ of the total number of such types of railway accidents. In turn, rolling stock derailment due to its unsatisfactory interaction with the rail track occurred in $27.3 \%$ of cases.

Such cases of railway traffic incidents are possible under that are necessary and sufficient condition.

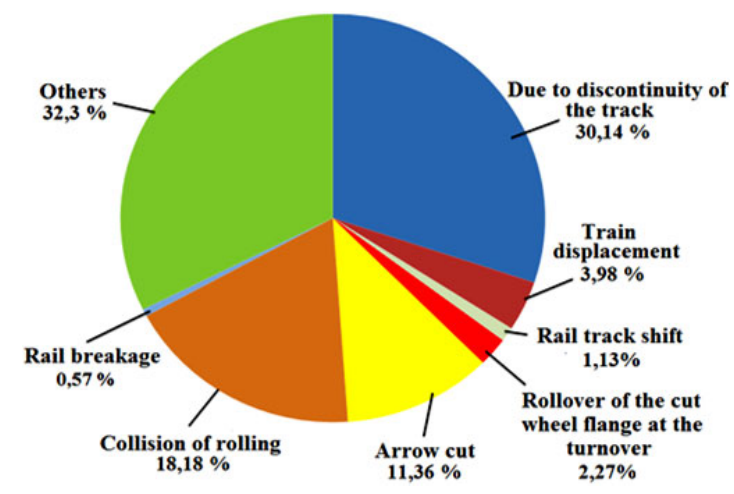

Fig. 2. Diagram of the distribution of reasons of freight wagons derailment for the last 5 years

The analytical expression of the required condition for rolling the wheel flange on the head of the rail has the form (Fig. 3) [11]:

$$
\left(P_{2} b_{2}+Y_{\mathrm{p}} r\right)-\left(P_{1} b_{1}+G_{\mathrm{\kappa}} l\right)>0,
$$

where $P_{1}, P_{2}-$ load on a wheel-pair, $k N ; b_{1}, b_{2}$ distance from the points of forces application $P_{1}, P_{2}$ to the middle circle of wheel rolling of the second wheel, $m ; Y_{\mathrm{p}}$ - frame strength, $k N ; G_{\mathrm{\kappa}}$ - weight of a wheelpair, $k N ; r$-radius of a wheel, $m ; 2 l$-distance between rolling circles of wheels, $m$.

The sufficient condition for rolling the wheel flange on the head of the rail is as follows:

$$
l \sin \theta_{\max }=f,
$$

where $\theta_{\max }$ - the maximum value of the angle, at which the axis of the track should return in cross-section plane of the railway, so that the flange is to be on the rolling surface of the rail head, rad; $f$ - height of the wheel flange, $m ; 2 l$ - distance between middle circles of wheels rolling of a wheel-pair, $m$.

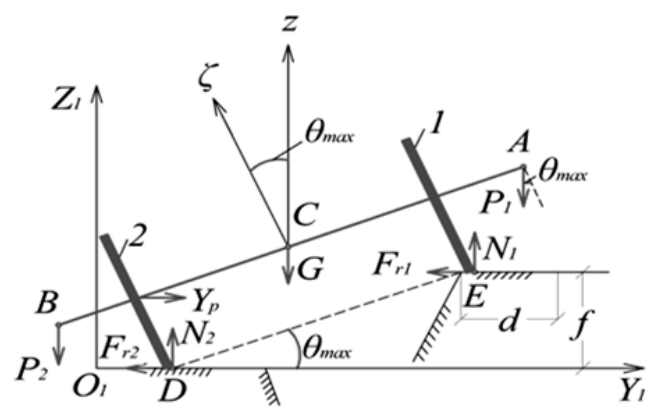

Fig. 3. Rolling wheel onto the rail head

After analyzing the cases of rolling stock derailment, which have occurred due to poor interaction of rolling stock and the rail track for the last five years, it is possible to distinguish the following characteristics:

- in the vast majority, empty wagons with a high center of mass (tank wagons, covered wagons), with a short base (hopper type) and with a rigid body (tank wagons) are liable to derailment; 
- wagon derailment took place both on the straight sections of the track and in the curved sections of the track with a radius of up to $1000 \mathrm{~m}$;

- wagon derailment took place both on the run and during braking;

- mainly, wagon derailment occurred at speeds above $50 \mathrm{~km} / \mathrm{h}$;

- technical state of rolling stock running gear and railway track had a significant impact on the development and occurrence of railway accidents.

In addition, there were occasions of freight wagons derailment, when parameters of their running gears and rail tracks approached the allowed limits.

Such cases of derailment are primarily due to structural disadvantages of bogie model 18-100, which contribute to safety indicators deterioration of freight trains. Among them there are such as [2]:

- large unsprung mass that interacts directly with the rails;

- intense wear of wedge oscillation dampers and noncompliance of damping characteristics in empty and loaded states of the wagon;

- insufficient constructive clearance and the level of friction forces between a truck bolster and a side bar of a bogie;

- intense wear of supporting surfaces of axial bearing units, axle-box slots;

- low critical speed in terms of movement stability.

This far-not complete list confirms that one of the main factors that leads to freight wagon derailment is structural features and the state of their running gears.

Therefore, investigation of the technical state of freight wagons running gears in the case of a railway accident is one of the most important identification and diagnostic tasks, the solution of which allows not only to determine the reasons for rolling stock derailment, but also to state limiting values of parameters of its technical condition, at which there is a threat to safety traffic.

\section{Development of an algorithm for assessing the impact of the technical state of wagons' running gears on their derailment}

Investigation of the technical state of wagons running gears is carried out both during the official investigation of railway traffic accidents and in the course of forensic railway-transport expertise. Such investigation is to compare the numerical values of actual parameters of wagons' running gears with the normative ones, establishing the conformity (non-conformity) of their numerical values, and, in case of non-conformity, referring to specific points of normative documents; the conclusion is issued whether the technical state of the running gear conforms to the requirements of normative documents or not.

In turn, actual (factual) parameters of the running gears of derailed wagons are determined within the framework of the official investigation on the basis of data obtained using special measuring devices (templates), and commission acts are issued. These acts are included into the materials of official investigation as well as the materials provided to the expert for investigation. Basic information of these documents is also put by the investigating judge into output data of the decision on the appointment of forensic railway-transport expertise [11].

When investigation the rail-transport incidents, there are some difficulties in investigation of the technical state of rolling stock.

One of the reasons is that its elements undergo significant force influence, which can lead to their deformation, destruction during rolling stock derailment. It results in the impossibility of establishing conformity of a large number of rolling stock parameters with the requirements of normative documents, whose portion of influence on the development of railway accident could be significant [14]. Also, when investigation the technical state, it is difficult to establish the origin of malfunctions of elements of the rolling stock structure, since the development of cracks in them, over-wearing can begin in periods, when their normal work is expected. Such malfunctions can occur both in operation and be the result of poorly done repairs.

One of the most difficult cases for investigation is rolling stock derailment, when technical state of its elements and the state of the rail track, according to the materials provided for research, have no deviations from permissible values. The causes of derailment in such cases are considered "hidden" and may be conditioned by simultaneous coincidence of a number of factors that form the most adverse (worst) combination of circumstances that developed by the state of the rolling stock and the section of the track on which the derailment took place. In addition, there are cases when there is a significant proportion of inaccurate information, which doesn't allow to identify the true cause of the rolling stock derailment [2].

In this case, it is possible to facilitate and speed up the implementation of forensic railway-transport expertise by constructing an algorithm for assessing the impact of the rolling stock technical state on the emergence and development of a railway accident.

This research algorithm should include the following steps (Fig. 4):

- collection of initial data on the state of the wagon running gears;

- verification of data on the state of the wagon running gears;

- choice of parameters for the wagon running gears and their evaluation criteria;

- comparison of numerical values of the parameters of wagon's running gears with the normative.

As a result of checking the parameters of the wagon's running gears, the conclusion is made about their technical state, which may be properly, faulty and non-operable at the moment of a railway accident. If the technical state of the wagon's running gears is not in a cause-and-effect relation with the railway-transport incident, then the corresponding conclusion about its study is issued.

Otherwise, if there is such a connection, then in order to be able to determine the influence of the technical condition of the wagon on the onset of a railway accident in the totality of circumstances accompanying the derailment, it is necessary to develop a computer model of the dynamics of a train with a detailed display of the 
rolling stock unit. Such model will cover a whole range of influential factors and identify the most significant of them with regard to the circumstances of derailment by means of a computer experiment.

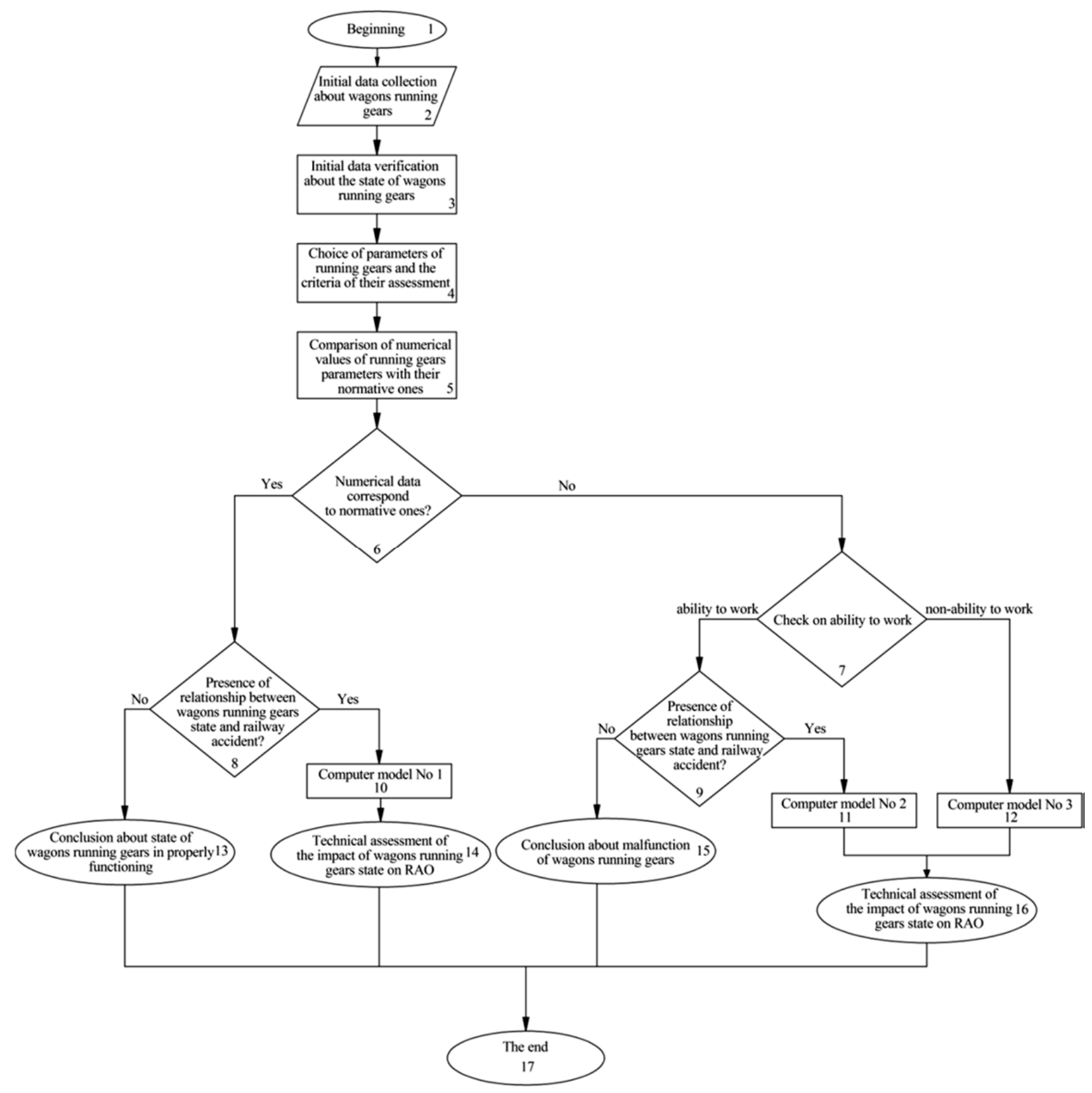

Fig. 4. Algorithm of investigation the technical state influence of freight wagons' running gears on railway accident occurrence

The process of constructing the model for determining possible causes of rail-transport incidents is in the following steps:

- analysis of information about the railway-transport accident;

- development of the spatial calculation scheme and the mathematical model of the wagon that derailed first;

- creation of the computer model of train dynamics with an acceptable degree of detail allowing to take into account a certain set of input parameters;

- verification of adequacy of the computer model;

- formation of a set of parameters that accompanied rolling stock derailment;

- conducting researches using a computer model;

- determination of the degree of influence of the parameters of wagon's running gears technical state on the railway-transport accident.

Of course, the choice and formation of parameters that accompanied rolling stock derailment depends on the type of a mathematical model. This can be a model of elements wear of rolling stock structure, their fatigue failure, a model of dynamic interaction of rolling stock and the rail track, etc.

For the mathematical model construction of rolling stock and the rail track interaction, the necessary parameters can be:

- speed of the train at the section of derailment;

- scheme of train formation regarding wagons loading and automatic coupling devices in the train;

- mode of train driving;

- characteristics of the first derailed wagon:

- type of a wagon, inertia and geometric parameters of the 
body;

- parameters of wagon's running gears with the display of their technical state (drifting of axle-box slots, wedges and axial bearings as well as characteristics of friction units):

- actual dimensions of wheels and wheel-pairs;

- parameters of the railway track, etc.

It should be noted that the connection between the process of derailment and any event factor cannot be established on the basis of logical consequences of only one calculation option, since the circumstances of derailment are inherent uncertainty, which is amplified by the dynamic formulation of the problem. Information obtained on the basis of the official investigation of a transport incident allows us, at the best, to formulate the list of factors pertaining to the incident with only a certain degree of certainty. It is impossible to find out what caused derailment with complete confidence, but it is possible to determine which factors among all possible contributed to the development of an emergency. This confidence should be based on statistical data obtained by conducting and analyzing multivariate calculations based on the developed model of rolling stock dynamics at the section of derailment [2].

Such model provides an opportunity to expand significantly the limits of the virtual experiment, to accelerate the process of investigation the dynamic parameters of rolling stock, to facilitate the establishment of limit values of the parameters of its technical state and to assess the consequences change of these parameters when investigation railway traffic accidents.

\section{Conclusions}

1. The analysis of the causes of rolling stock derailment on the railways of Ukraine for the past five years has shown that more than half of the total number of derailments is due to rolling of the wheel flange of the wheel-pair onto the rail head in the presence of malfunctions of freight wagons' running gears.

2. To determine the influence of the technical state of wagons' running gears on the process of their derailment, the algorithm for research that includes a computer experiment was developed.

3. The developed algorithm for investigation the causes of rolling stock derailment allows to determine the limits of the parameters of its technical state, to evaluate the consequences of these parameters change, transferring the formation of requirements for the system of rolling stock maintenance into the plane of evidentiary dynamics.

\section{Bibliography}

1. I.V. Klimenko. Development of theoretical bases and methods of assessment improving the movement safety of the railway rolling stock: diss. ... dr. tech. sciences: 05.22.07, DNUZT, 284 p., (2015)
2. R.Yu. Demin. Development of methods and means of research on maintenance of technical operation of railway rolling stock: diss. ... dr. tech. sciences: 05.22.07, Volodymyr Dahl East Ukrainian National University, 475 p., (2018)

3. V.S. Lysyuk. Causes and the mechanism of the vanishing wheel from the rail. The problem of wear of wheels and rails, publ. Transport of Russia, 215 p., (2002)

4. A.N. Savchuk, A.V. Shatunov, A.G. Reidemeister, M.A Hrychaniy, V.A. Ryzhov, M.I. Lukhanin. Improving the dynamics of empty wagons on running gears model 18-100, Bulletin of the DNUZT, №18, p. 137-142, (2007)

5. S.V. Miamlin, L.O. Nedouzh, A.O., Shvets. Technical condition of the side bearing as one of the factors influencing the dynamics of freight wagons, Donetsk iof Railway Transport, №35. p. 65-72, (2013)

6. V.D. Danovich, V.V. Rybkin, A.G. Reidemeister, N.V. Khalipova, A.P. Tryakin. On the issue of stability against wheel rolling in on the rail for empty freight wagons, Bulletin of the DNUZT, №3, p. 90-96, (2004)

7. The investigation of derailments, Indian railways institute of civil engineering, Pune, 400 p., (2014)

8. X. Liu, M.R. Saat, C.P.L Barkan. Rail Transportation and Engineering Center, Department of Civil and Environmental Engineering, University of Illinois at UrbanaChampaign, 205 North Mathews Avenue ХангVolume: 2289, issue: 1, p. 154-163. (2012)

9. V.G. Ravlyuk. Determination of the technical condition of axial bearings of rolling stock by the method of vibrodiagnostics, Eastern-European Journal of Enterprise Technologies, №2 (7), p. 11$15,(2015)$

10. L.O. Gracheva, A.D. Khamoev, L.N. Kosarev, A.V. Martynyuk. Causes derailment of rolling stock in trains and measures to prevent accidents and crashes, publ. Intext, 93 p., (1995)

11. E.N. Sokol. Derailment and collisions of rolling stock (Forensic Expertise. Elements of the theory and practice), publ. Transport of Ukraine,. 386 p., (2004)

12. D.V. Bobyr, I.V. Bolzhelyarsky. Establishment of the technical condition of rolling stock in the forensic railway transport expertise, Theory and practice of forensic expertise and forensic science, №10, 484-491 p., (2010)

13. Analysis of the railway traffic safety in the structure of Ukrzaliznytsia for 2014-2018 years, Kyiv, Ukrzaliznytsia (2014-2018).

14. M. Sysyn, U. Gerber, O. Nabochenko, D. Gruen, F. Kluge Prediction of Rail Contact Fatigue on Crossings Using Image Processing and Machine Learning/Methods, Urban rail transit, №5(2), pp. 123-132, (2019). 